\title{
Thermal comfort evaluation in Tehran metro using Relative Warmth Index
}

\author{
${ }^{1}$ M. Abbaspour; ${ }^{2}$ M. J. Jafari; ${ }^{3}$ N. Mansouri; ${ }^{3}$ F. Moattar; ${ }^{3}$ N. Nouri; ${ }^{3}$ M. Allahyari \\ ${ }^{I}$ Department of Mechanical Engineering, Sharif University of Technology and Graduate School of the Environment \\ and Energy, Science and Research Branch, Islamic Azad University, Tehran, Iran \\ ${ }^{2}$ Department of Occupational Health, School of Public Health, Shahid Beheshti University of Medical Science, \\ Tehran, Iran
}

${ }^{3}$ Department of Environmental Engineering, Graduate School of the Environment and Energy, Science and Research Branch, Islamic Azad University, Tehran, Iran

Received 1 March 2007; revised 28 March 2008; accepted 12 April 2008

\begin{abstract}
Underground railway systems, can generate heat from their operations to raise the temperatures of carriages and the station substantially. This may lead to passenger discomfort and complain especially in warm weather conditions that prevail in Tehran if underground environment is not cooled. Transportation air conditioning Committee of American Society of Heating, Refrigerating and air-conditioning Engineers proposed the Relative Warmth Index for thermal comfort design and investigation in subway environment. In this research, thermal comfort at Tehran metro stations and carriages of lines 1 and 2 has been studied using this index. The measurements were taken during two periods of September 2006 and July 2007 at different zones of stations. For this purpose, temperature, relative humidity and air velocity were measured at different times. The status of the air-conditioning systems together with passenger traffic was also recorded. A total number of 231 measurements including 114 and 117 measurements were carried out in September 2006 and in July 2007 respectively. The measurements in September 2006 did not exceed the thermal limit. However, it did exceed in July 2007. In comparison, with thermal comfort level of metros all over the world, Tehran Metro stands in an acceptable condition, while the maximum capacity of air-conditioning systems was not used, if so the thermal comfort condition would be better.
\end{abstract}

Key words: Passenger discomfort, relative humidity, subway, underground railway

\section{INTRODUCTION}

Metro plays a significant role in present public transportation in order to improve the quality and to reduce the road congestion, as well as to fill gaps of insufficient public transport and road surface capacity (Nieuwenhuijsen et al., 2007). Residents in most urban areas spend a considerable amount of time commuting which is estimated to be $7 \%$ of daily time (Jenkins et al., 1992). The concentrations of air pollutants in road transportation carriages are extraordinary high. Other researchers found them to be 5 times higher than in the general urban environment (Fernandez and Ashmore 1995; Tian Tian et al., 2007). Underground railway transportation has several advantages over the other public transportation systems. Generally speaking, metro trains need 50-70\% less energy for carrying the

$\triangle$ *Corresponding Author Email: nmansourin@gmail.com Tel.: +9821 4486 5004; Fax: +9821 44865002 same amount of loads or passengers. As a result, indirect substantial profit from its application has caused it to have a worldwide development. Environmental control system of the underground mass rapid transit (MRT) system must incorporate special design features in tunnel ventilation, smoke exhaust, air conditioning and so on which make it significantly more complicated than that of a commercial building (Shih-Cheng and Jen-Ho, 2004).

Underground railway systems can generate enough heat from their operations to raise station and vehicle temperatures substantially (Overmeyer, 1961). This may lead to passenger discomfort and complain in warm weather conditions if the underground railway environment is not cooled. The heat generated by train motors, electric lighting, human body etc is so great that excessive temperatures would prevail in summer 
unless a volume of air in excess of that required for breathing is supplied (Ampofo et al., 2003 ; Glover, 2001). Most new transit systems are equipped with air conditioned carriages. The air conditioning hardware is of the vapor-cycle type resulting in great dissipation from the condensers of each air conditioning unit equal to $125 \%$ of the heat removed from the car interior. Since the power required per car for air conditioning may be as much as $50 \mathrm{kw}$, the energy and heat dissipation load of the air conditioners are significant contributors to the overall cooling load of subway system (SES, 1976). By 2007, Tehran metro had $90 \mathrm{~km}$ length, 51 stations and 3 lines in operation. Regarding its length, Tehran Metro stands among the first 24 metros in the world. By that year, totally $8110 \mathrm{~km}$ of constructed metros was utilized in the world in which Tehran underground shares 1.1\% (Metro Bits'Website, 2008). Fig. 1 shows operating lines 1, 2 and 5 in Tehran metro. Four new lines are under construction in Tehran metro at present. Promoting the quality of comfort standards requires thermal comfort improvement at the metro environment to encourage people to use metro as the main public transportation system in Tehran. For this purpose, comprehensive studies on thermal comfort status and probable needs are required.

Transportation Air Conditioning Committee of American Society of Heating, Refrigerating and AirConditioning Engineers (ASHRAE) proposed RWI for thermal comfort design and investigation in metro environment. Now, the application of RWI in design process of metro systems is a common practice but it has not been widely used to evaluate thermal conditions in operating underground railway systems. The RWI is a function of various parameters, including temperature, relative humidity, air velocity, individual clothing, and metabolic rate (SES, 1976; Ampofo et al., 2003). ASHRAE also proposed the thermal comfort classification table associated with RWI. Thus, it is possible to evaluate the thermal comfort status in metro environment using RWI. Other indices including predicted mean vote (PMV) and predicted percentage of dissatisfied (PPD) have been used by some researchers to evaluate an existing metro environment (Ampofo et al., 2004; Fanger, 1970; ISO 7730, 1994; Humphreys et al., 2002). Another similar study was conducted by Oakland on thermal comfort in trains

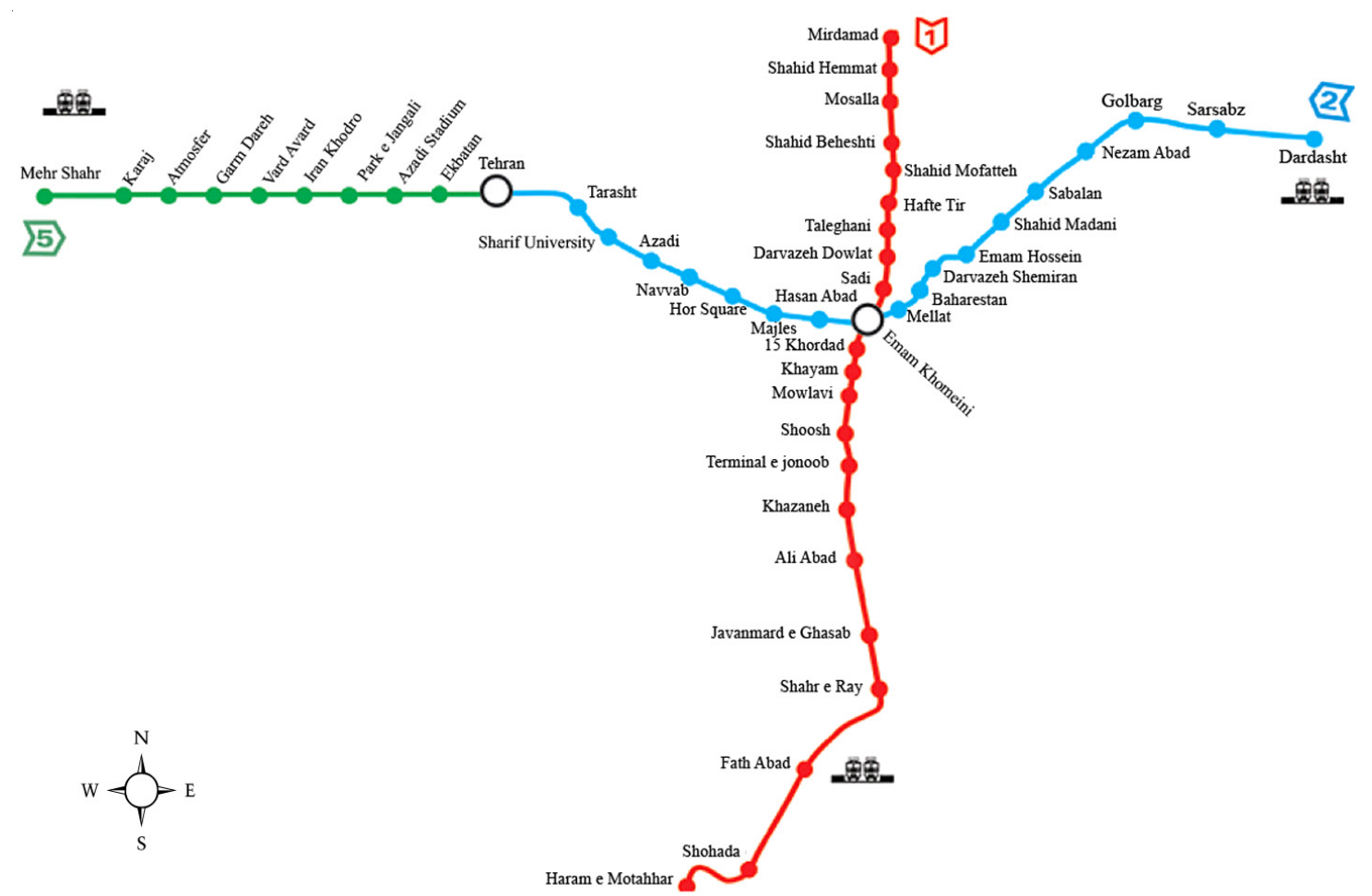

Fig. 1: The map of lines 1, 2 and 5 of Tehran Metro

(Tehran Metro Public Relations, 2006) 
and other enclosed spaces of London underground, looking in particular at high temperature in the tube environment. They found that, apart from temperature, relative humidity and air particulates play a significant role in thermal comfort of metro stations and carriages (Oakland Ltd, 2002).

Arsenal research in Austria in 2002, organized a conference - Mobile Air Conditioning - on the subject but none of the participants was able to define an acceptable thermal comfort criterion for an underground railway environment. Regarding metro design measures, RWI is suggested by many countries including USA (SES, 1976). This index considers all main parameters that affect thermal comfort in metro environment. The application of this index to evaluate present thermal status of Tehran metro is expected to indicate real thermal status of this environment and makes it possible to evaluate the design and execution of the existing system as well.

\section{MATERIALS AND METHODS}

This study was a part of a comprehensive research on air quality and thermal comfort in metro carriages and stations initiated by Tehran Metro Authority. The research plan was conducted to study lines 1 and 2 of Tehran metro in 2006 -2007. For this purpose, 6 stations and all carriages in lines 1 and 2 were studied. Total of 231 measurements carried out during two periods in September 2006 and July 2007. Considering that in September evaporating refrigerating systems and carriages' air-conditioners were not in full operation. September measurements were selected to evaluate thermal conditions in a maximized passenger period. The number of passengers using metro is usually maximized with inauguration of schools and educational institutes In September. July measurements were conducted to evaluate the air conditioning and ventilation system of metro in the warmest period of year. The measurement times were selected based on the hours of metro activity that was between $6: 30 \mathrm{am}$ and $23 \mathrm{pm}$. Temperature, relative humidity and air velocity together with air-conditioning flow rate were measured at different times in selected points in passenger carriages, driver cabins and stations, which include station entrances, ticket halls, three points on platforms, entrance and exit of air-conditioners. Six underground stations including, Mirdamad, Darvazeh Dowlat, Panzdah Khordad and Imam Khomeini stations, on line 1 and Azadi and Imam Khomeini stations on line 2 were selected for this study. A total number of 114 measurements have been done in September 2006 and 117 measurements in July 2007. Temperature and relative humidity were measured using a hygrometer LM-81 HT made by Lutron Company, Taiwan. It has a high accuracy, quick response within a time span and saving data in the memory for measuring time interval. Its accuracy for relative humidity was $0.1 \%$ and for temperature was $0.1^{\circ} \mathrm{C}$. A portable hot wire anemometer provided quick response and relatively high accurate reading even at low air velocities with digital readability, Tecpel AVM-714 made by Lutron Company, Taiwan, was used for measuring air velocity in selected points. Its small sensor and a ldong probe made it suitable for testing air conditioning ducts, entrances and diffusers. The resolution of readings was $0.1 \mathrm{~m} / \mathrm{s}$. All instrumentations used in this study were calibrated prior to each series of measurements. Finally RWI was calculated for each point by a method using the following equations (SES, 1976):

$$
\begin{aligned}
& R W I=\frac{M\left(I_{c w}+I_{a}\right)+1.13(t-95)+R I_{a}}{70(1.73-P)} \\
& (1-a) \quad\left(P_{V}>0.67 \text { in Hg }\right) \\
& R W I=\frac{M\left(I_{c w}+I_{a}\right)+1.13(t-95)+R I_{a}}{74.2} \\
& (1-b) \quad\left(P_{V} \leq 0.67 \text { in Hg }\right)
\end{aligned}
$$

Where:

$\mathrm{M}=$ metabolic rates, Btu/h. $\mathrm{ft}^{2}$

$\mathrm{I}_{\mathrm{cw}}=$ insulation of clothing based on wet cloth assumption, clo coeficient

$I_{a}=$ insulation effect of air boundary layer, clo coeficient $\mathrm{t}=$ dry-bulb air temperature, ${ }^{\circ} \mathrm{F}$

$\mathrm{t}-95=$ difference between dry-bulb temperature and average skin temperature just before a person feels uncomfortably warm, ${ }^{\circ} \mathrm{F}$

$\mathrm{R}=$ mean incident radiant heat from sources other than walls at room temperature, $\mathrm{Btu} / \mathrm{h}$. $\mathrm{ft}^{2}$

$\mathrm{P}=$ vapor pressure of water in air, in of mercury

Saturated vapor pressure $\left(\mathrm{P}_{\mathrm{S}}\right)$ and vapor pressure $\left(\mathrm{P}_{\mathrm{V}}\right)$ at $t$ were estimated using equations 2 and 3 (Chadderton 1997). $P_{v}$ was less than 0.67 at all sites. Thus, RWI in the study came from relation (1a).

Metabolic rate, insulation of clothing based on wet cloth assumption and activity induced velocity was driven out of Table 1. Table 3 shows the comfort classes based on ASHRAE recommendations using RWI. 
In present study, this table was used to evaluate thermal comfort in Tehran metro.

$\log P_{S}=30.59051-8.2 \times \log T+2.4804 \times$

$10^{-3} T-\frac{3142.31}{T}$

$P_{V}=P_{s l}-1013.25 \times 6.66 \times 10^{-4} \times\left(t-t_{s l}\right)$

Where:

$\mathrm{P}_{\mathrm{S}}=$ Saturated vapor pressure at temperature $\mathrm{t}, \mathrm{kpa}$

$\mathrm{P}_{\mathrm{sl}}=$ Saturated vapor pressure at wet bulb temperature

$\mathrm{t}_{\mathrm{s} 1}$ using equation 2 , $\mathrm{kpa}$

$\mathrm{P}_{\mathrm{V}}=$ Vapor pressure at dry bulb temperatures, $\mathrm{kpa}$

$\mathrm{T}=$ Absolute temperature, $\mathrm{K}$

$\mathrm{t}_{\mathrm{sl}}=$ Wet bulb temperature, ${ }^{\circ} \mathrm{C}$

$\mathrm{t}=$ Dry bulb temperature, ${ }^{\circ} \mathrm{C}$

In this manner, a warmth level can be expressed quantitatively for various combinations of activities and conditions (Pribek, 1989a; Pribek 1989b). ASHRAE has made a frequency distribution of the percentage of test subjects who feel comfortable when exposed to the nominal ASHRAE comfort classifications. A quantitative relationship among ASHRAE comfort designations, the frequency distribution and RWI is shown in Fig. 2, which gives the percentage of people not feeling comfortable, those desiring a cooler condition, in environments with various RWI values
(Ampofo et al., 2004). Table 2 shows selected and calculated values needed for calculating RWI using Eq. $1 \mathrm{a}$ and $\mathrm{b}$ at various locations in the underground stations (SES, 1976).

\section{RESULTS AND DISCUSSION}

Temperature, Relative humidity and calculated RWI values are presented as box plots. Spacing between different parts of the box helps to indicate variance, skewness and identify outliers. Each part represents one quartile of data distribution. The extreme lines represent maximum and minimum of data. The middle rectangle shows $50 \%$ of the data distribution.

The descriptive statistics of relative humidity values at different locations during two periods of measuring time are shown in Figs. 3 and 4. The ASHRAE-55 standard recommends a range of $30 \%$ to $60 \%$ as the comfort levels for relative humidity (ASHRAE Standard 55-2004). The upper limit has been set considering corrosion effect of humidity, its effect on growth of micro organisms and condensation in cooler environments rather than comfort issues.

The Figs. 3 and 4 show that in September 2006, not only the relative humidity in almost all of the measurements was lower than upper limit of recommended range of ASHRAE- 55 but also less than $25 \%$ of the measurements were classified as dry. The statistics show that in July 2007, the warmer the outside air the drier the inside environment has been resulted.

Table 1: Insulating effect of clothing at various activity levels

\begin{tabular}{lccc}
\hline Activity & $\begin{array}{c}\text { Metabolic rate M, Btu per } \\
\text { h.sq.ft }\end{array}$ & $\begin{array}{c}\text { Insulation } \mathrm{I}_{\mathrm{CW}}, \mathrm{Clo} \\
\text { (Wet close assumption) }\end{array}$ & $\begin{array}{c}\text { Activity induced- } \\
\text { velocity } \mathrm{V}_{\mathrm{b}}, \mathrm{fpm}^{\mathrm{fpm}}\end{array}$ \\
\hline Basal & 15 & 0.6 & 0 \\
Seated at rest & 20 & 0.6 & 20 \\
Seated vending fares & 25 & 0.4 & 50 \\
Standing vending fares & 28 & 0.5 & 30 \\
Standing or occasional stroll & 39 & 0.4 & 100 \\
Walking, 2 mph & 39 & 0.4 & 200 \\
Walking, 3 mph & 54 & 0.35 & 300 \\
Walking, 4 mph & 71 & 0.3 & 400 \\
\hline
\end{tabular}

Table 2: Key values for calculating RWI

\begin{tabular}{|c|c|c|c|c|c|c|c|}
\hline Location & $\begin{array}{c}\mathrm{M} \\
\mathrm{Btu} / \mathrm{h} . \mathrm{ft}^{2}\end{array}$ & $\begin{array}{c}\mathrm{I}_{\mathrm{a}} \\
\text { clo }\end{array}$ & $\begin{array}{l}\mathrm{I}_{\mathrm{CW}} \\
\text { clo } \\
\end{array}$ & $\begin{array}{c}\mathrm{V}_{\mathrm{a}} \\
\mathrm{fpm}\end{array}$ & $\begin{array}{c}V_{b} \\
\text { fpm }\end{array}$ & $\begin{array}{r}V_{\mathrm{r}} \\
\mathrm{fpm}\end{array}$ & $\begin{array}{c}\mathrm{R} \\
\text { Btu/h.ft }\end{array}$ \\
\hline Entrance & 54 & 0.25 & 0.35 & 370 & 300 & 670 & 10 \\
\hline Ticket sale hall & 54 & 0.3 & 0.35 & 171 & 300 & 471 & 0 \\
\hline Platform & 39 & 0.4 & 0.4 & 370 & 300 & 670 & 0 \\
\hline Wagon & 28 & 0.45 & 0.5 & 110 & 50 & 160 & 0 \\
\hline Head & 29 & 0.55 & 0.3 & 50 & 50 & 100 & 0 \\
\hline
\end{tabular}


Due to lower humidity in stations (below about 30\% relative humidity) It is expected to dry out the nose, eyes and throat, leading to discomfortibility of passengers (Fig. 4). The Low humidity air in stations also allows dust to circulate in the air which may lead to throat/lung problems, eyes and nose sores, etc.

Evaporation from air washers installed in stations' ventilation system, peoples breathing and body evaporation are the main sources of humidity in the underground environment, but the measurements showed the lower rate of relative humidity in almost all of measuring points especially in warmer period such as July so more evaporation rates are required by air washers to normalize the relative humidity in stations in summer time.

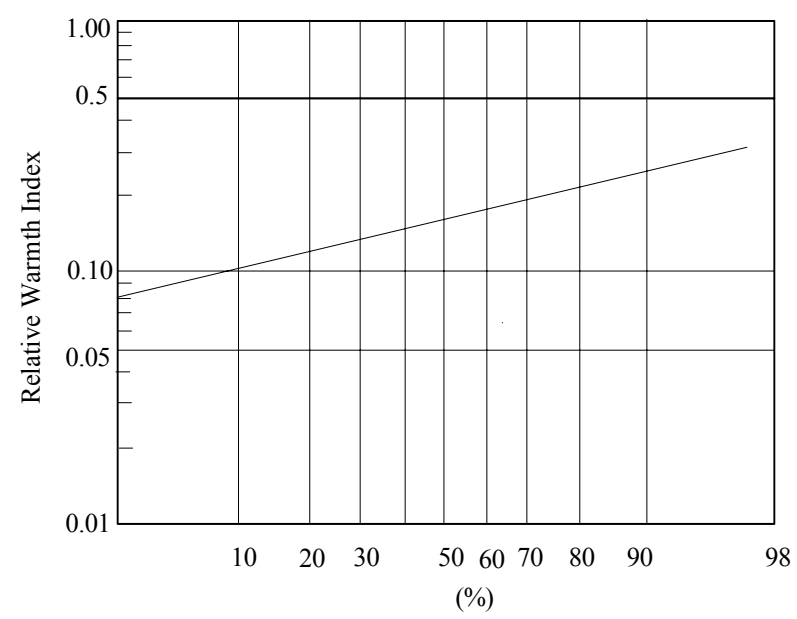

Fig. 2: Percentage of people who want a cooler environment in summer, (Ampofo et al., 2004)

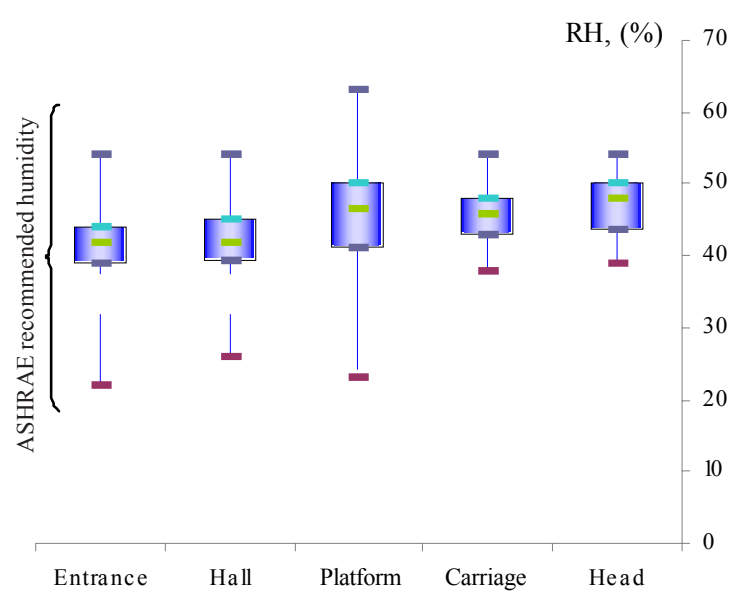

Fig. 3: Descriptive statistics of humidity values at different locations in underground stations of Tehran metro, (September 2006)
The lower difference between relative humidity on the platform and station entrance not only, approve the lower efficiency of the air washers to spray and evaporate water but also resulting in rising relative humidity and lowering the air temperature. Thus, it resulted on more discomfort in July 2007 rather than that of September 2006 in the stations.

Figs. 5 and 6 show the descriptive statistics of dry bulb temperature values at different locations during two periods of measurements. However, higher dry bulb temperatures at the entrances of stations could be due to warmer conditions out side the stations, but the measurements in September 2006 were mainly found to be within the recommended range of ASHRAE standard values for dry bulb temperature.

Whereas the mean values of dry bulb measurements in July 2007 were significantly higher than those of September 2006 and the ASHRAE standard values as well. It seems that the evaporative ventilation system did not operate as desired thus it couldn't cool down the stations environment satisfactorily in the outside warm condition such as July time. The high values of temperature in platforms, halls and station entrances

Table 3: ASHRAE comfort classification using RWI (ASHRAE 62-1989)

\begin{tabular}{ll}
\hline Comfort classification & RWI \\
\hline Warm & 0.25 \\
Slightly warm & 0.15 \\
Comfortable & 0.08 \\
Slightly cool & 0.00 \\
\hline
\end{tabular}

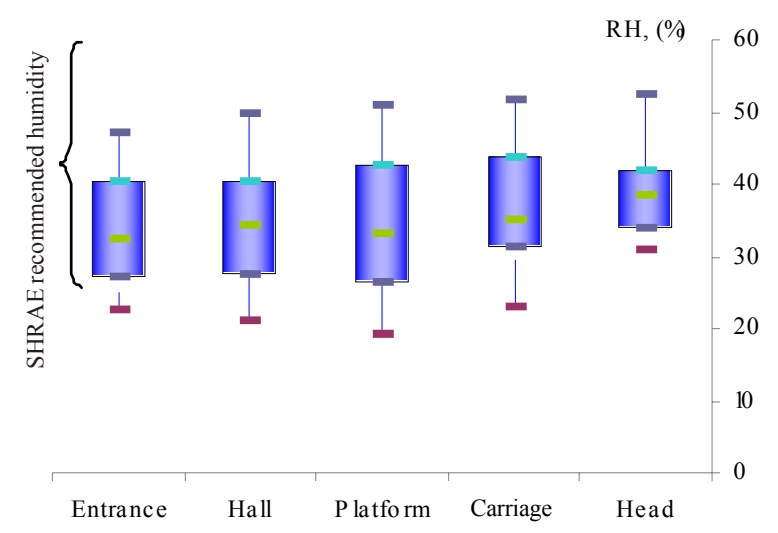

Fig.4: Descriptive statistics of humidity values at different locations in underground stations of Tehran metro, (July 2007) 
approve this opinion well. In the other hand, dry bulb temperatures in carriages were lower than other points in the stations which show the good operation of carriage air conditioning system to prepare an acceptable environment for passengers.

Figs. 7 and 8 show the descriptive statistics of calculated RWI values at different locations during two periods of measurements. Generally it can be concluded that although the thermal comfort in Tehran metro was relatively acceptable but ideal thermal comfort has not been achieved in the stations. This agrees with other researches (Ampofo et al., 2004), that believe the acceptable thermal comfort criteria say for an office may not be achievable in an underground railway environment. (ASHRAE insights, 2002; ASHRAE 621989, 1989; ASHRAE, Addendum to Standard 62-1989, 1989). Parker (1972) believes that dry bulb temperature, air velocity and relative humidity are important in passenger environment study but radiation is less important. (Bedford, 1936; Hickish, 1955) present study

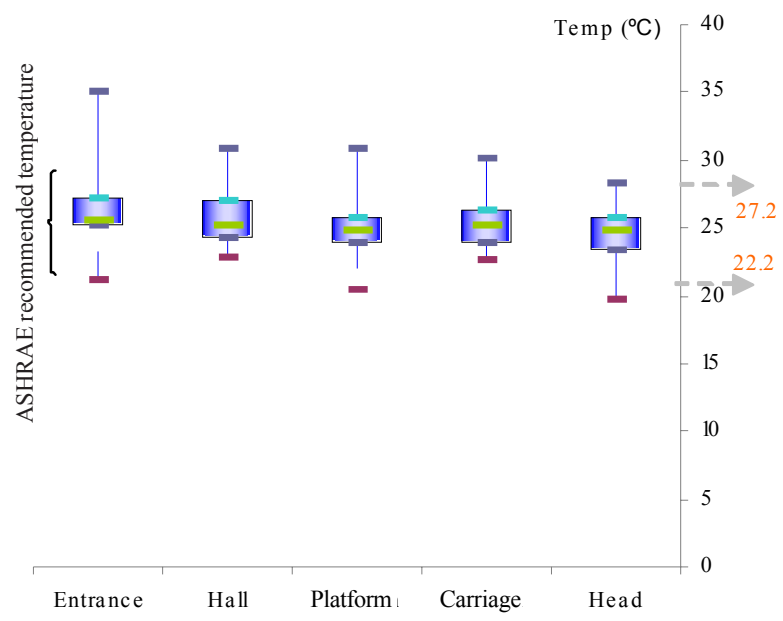

Fig. 5: Descriptive statistics of dry bulb temperature values at different locations in underground stations of Tehran metro, (September 2006)

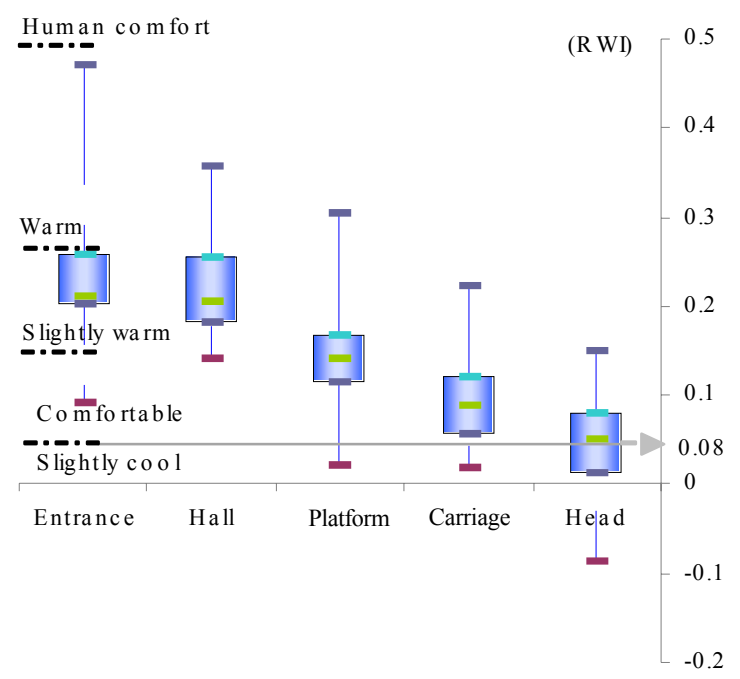

Fig. 7: Descriptive statistics of calculated RWI values at different locations in underground stations of Tehran metro, (September 2006)

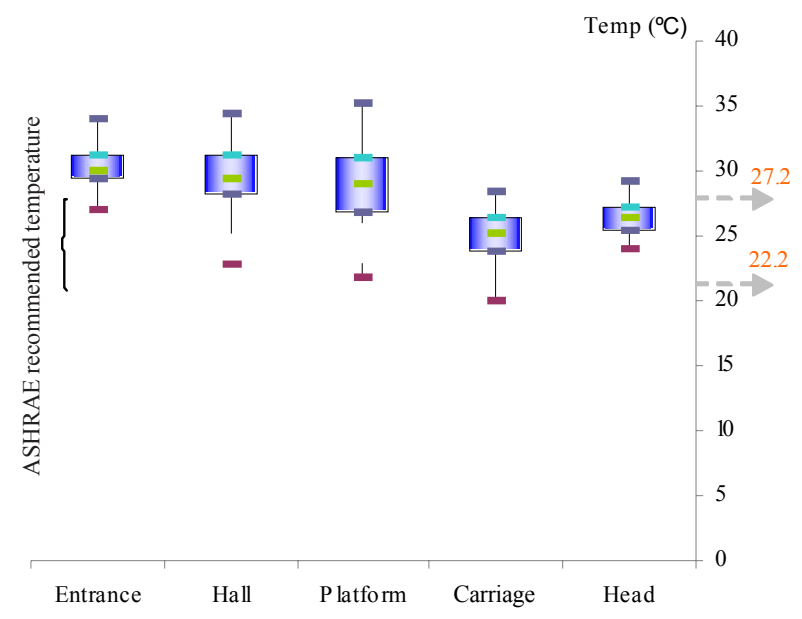

Fig. 6: Descriptive statistics of dry bulb temperature values at different locations in underground stations of Tehran metro, (July 2007)

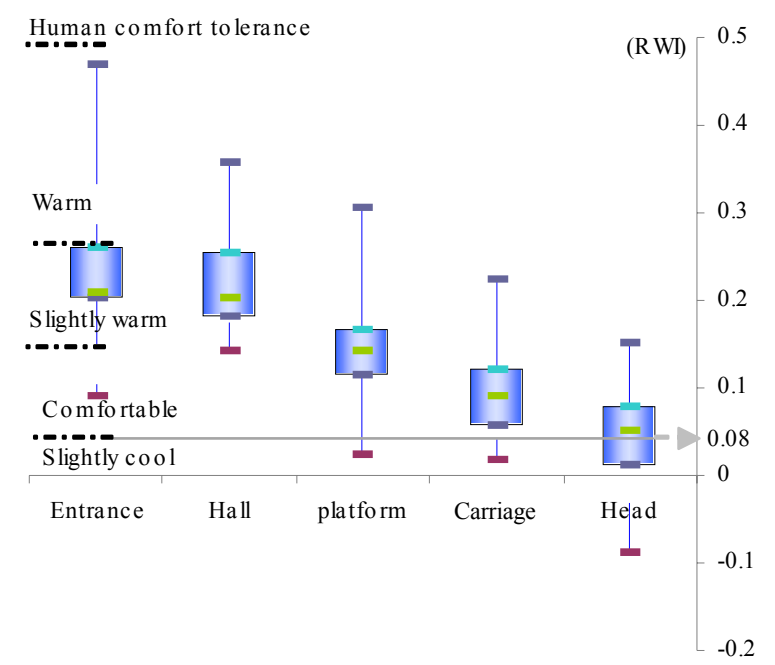

Fig. 8: Descriptive statistics of thermal comfort using RWI values at different locations in underground stations of Tehran metro, (July 2007) 
shows that in closed area such as carriages, as it is expected the air velocity does not play a significant role in thermal comfort as it is expected.

According to Building Services Research and Information Association (BSRIA) report, in modern underground tube stations (MUTS) in about $97 \%$ of the time thermal condition was slightly cool to warm. Present study shows that thermal comfort in Tehran metro stations as MUTS, are warm. This shows that thermal comfort is not achievable in stations in hot summer days. Applying RWI values obtained for halls and platforms to Fig. 2 shows that, more than $98 \%$ of the people in halls and platforms of Tehran metro desire cooler environment in summer. Even in September, more than $80 \%$ of the people in halls and platforms prefer a cooler environment (Booth and Galliers, 2001). Thus, it is necessary to turn on more air conditioners in these periods of the year. Modification of the air conditioning systems installed at the stations is also suggested. The results show that, thermal condition in Tehran metro stations is similar to od underground tube stations (OUTS) in BSRIA report. Thermal condition in Tehran metro stations is also similar to Budapest underground in summer time which has been studied by (Ordody, 2000). He measured the thermal comfort in the passenger areas of five deep level stations, $20-30 \mathrm{~m}$ deep down from the surface, of the Budapest underground. He also measured dry bulb temperature, relative humidity and air velocity at typical areas in the occupied zones of the metro stations. During the measurements, however, the researcher reported that there was a case when the PPD went up to $80 \%$ (Ordody 2000; Aarnio et al., 2005; Overmeyer, 1961; Pribek, 1989). The calculated RWI values in underground carriages, compared with other studies indicate an acceptable and standard level of thermal comfort in Tehran underground carriages. In a study project carried out by Arsenal Research, commissioned by the Federal Ministry of Transport, Innovation and Technology of Austria, the real thermal situation of selected railway vehicles in everyday regular service has been investigated. All selected vehicles had air conditioning, some fully and others only partly. The aim of the investigation was to optimize passenger thermal comfort by studying the coactions of effective parameters such as air temperature, surface temperature, air humidity, air velocity, clothing and activity level. The final result has showed the thermal comfort condition to be slightly warm (Ampofo et al., 2004), but present study (Figs. 5 - 8) indicated suitable level of thermal comfort even in the warmest time of the summer in July.

\section{ACKNOWLEDGMENTS}

The authors wish to appreciate the General Manager of Tehran and Suburban Metro for his sincere assistance.

\section{REFERENCES}

Aarnio, P.; Yli-Tuomi, T.; Kousa, A.; Mäkelä, T.; Hirsikko, A.; Hämeri, K.; Räisänen, M.; Hillamo, R.; Koskentalo, T. Jantunen, M., (2005). The concentrations and composition of and exposure to fine particles $\left(\mathrm{PM}_{2.5}\right)$ in the Helsinki subway system, Atmos. Environ., 39 (28), 5059-5066.

Ampofo, F.; Maidment G.; Missenden, J., (2003). Underground railway environment in the UK, Part 3: Methods of delivering cooling, Appl. Therm. Eng., 24 (5-6), 647-659.

Ampofo, F.; Maidment G.; Missenden, J., (2004). Underground railway environment in the $\mathrm{UK}$, Part 1: Review of thermal comfort, Appl. Therm. Eng., 24 (5-6), 611-631.

ASHRAE, (2004). ASHRAE Standard 55-2004. Thermal environmental conditions for human occupancy, American Society of heating ventilation and air conditioning.

ASHRAE, (2002). ASHRAE Insights, American Society of heating ventilation and air conditioning guidelines for Railway HVAC. 17 (4).

ASHRAE, (1989). ASHRAE standards 62-1989, Ventilation for acceptable indoor air quality, American Society of heating ventilation and air conditioning.

ASHRAE, (1989). Addendum to standard 62-1989: New ventilation rates proposal, American Society of heating ventilation and air conditioning, 10-11.

Bedford, T., (1936). The warmth factor in comfort at work, Medical Research Council and Department of Scientific and Industrial Research, Industrial Health Research Board Report, No. 76.

Booth, W.; Galliers, S., (2001). Quality environments for public transport buildings, BSRIA report, DETR Ref. No: CI 11-38/6/ 160, Ref. No: SS70180.

Chadderton, D., (1997). Air Conditioning, a practical introduction, Thomson Science professional, $2^{\text {nd. }}$ Ed., Chapter 2, 37-67.

Cheng, S.; Ho, L., (2004). Influence of platform screen doors on energy consumption of the environment control system of a mass rapid transit system: case study of the Taipei MRT system, Energ. Convers. Manage., 45 (5), 639-650.

Fanger, P., (1970). Thermal Comfort: Analysis and application in Environmental engineering, McGraw-Hill.

Fernandez, A.; Ashmore, M., (1995). Exposure of commuters to carbon monoxide in Mexico City II: Comparison of in vehicle and fixed - site concentrations, J. Expo. Anal. Environ. Epid., 5 (4), 495-510.

Glover, J., (2001). Flywheels for traction power: energy-saving potential of the Urenco trackside energy storage system, Modern Railways (June), 14.

Hickish, D., (1955). Thermal sensations of workers in light industry in summer, A field study in southern England, J. Hyg., Camb., 53 (1), 112-113. 
Humphreys M.A. and Nicol J.F. (2002) The validity of ISOPMV for predicting comfort votes in every-day thermal environments. Energ. Build., 34 (6), 667-684

ISO 7730, (1994). Moderate thermal environments determination of the PMV and PPD indices and specification of the conditions for thermal comfort, ISO, Geneva

Jenkins, P.; Philips, T.; Mulbert, J.; Hui, S., (1992). Activity patterns of Californians: Use of and proximity to indoor pollutant sources. Atmos. Environ., 26A (12), 291-297.

Metro Bits' Website, (2008). http://www.mic-ro.com/metro/

Nieuwenhuijsen, M.;Gomez-Perales, J.; Colvile, R., (2007). Levels of particulate air pollution, its elemental composition, determinants and health effects in metro systems, Atmospher. Environ., 41 (37), 7995-8006.

Oakland Innovation and Information Services Ltd, (2002). Cambridge Science Park, Milton road, Cambridge, CB4 0FH, Thermal comfort on trains.

Ordody, P., (2000). Thermal comfort in the passenger areas of the Budapest Metro, Periodica Polytechnica Ser. Mech. Eng., 44 (2), 309-317.

Overmeyer, E. J., (1961). How face air velocity affects airplane passenger comfort, ASHRAE J., 3 (8), 41 - 44.
Parker, J., (1972). Air-conditioning related to passenger environment, C32/72, Railway Division Conference on Passenger Environment, IMechE, 58-63.

Pribek, P., (1989a). Summary and evaluation of the measurement of air velocity in deep stations, Metro Fomérnökség, Budapest.

Pribek, P., (1989b). Comparative evaluation of air measurements of metro lines, Metró Fomérnökség, Budapest.

SES, (1976). Subway Environmental design handbook, principles and applications, Associate Engineers, $2^{\text {nd. Ed. 1, }}$ March.

Shih-Cheng, H.; Jen-Ho, L., (2004). Influence of platform screen doors on energy consumption of the environment control system of a mass rapid transit system: case study of the Taipei MRT system, Energ. Convers. Manage., 45 (5), 639-650.

Tehran Metro Public Relations, (2006), Tehran and suburban metro map, http://www.tehranmetro.com.

Tian-Tian L.; Yu-Hua B.; Zhao-Rong L.; Jin-Long L., (2007). In-train air quality assessment of the railway transit system in Beijing: A note, Transportation Research Part D., 12, 64-67.

\section{AUTHOR (S) BIOSKETCHES}

Abbaspour, M., Ph.D., Professor, Department of Mechanical Engineering, Sharif University of Technology and Graduate School of the Environment and Energy, Science and Research Branch, Islamic Azad University,

Tehran, Iran.Email:m-abbaspour@jamejam.net

Jafari, M. J., Assistant professor, Department of Occupational Health, School of Public Health, Shahid Beheshti University of Medical Science, Tehran, Iran. Email: jafari1952@yahoo.com

Mansouri, N., Assistant professor, Department of Environmental Engineering, Graduate School of the Environment and Energy, Science and Research Branch, Islamic Azad University, Tehran, Iran. Email:nmansourin@gmail.com

Moattar, F., Professor, Department of Environmental Engineering, Graduate School of the Environment and Energy, Science and Research Branch, Islamic Azad University, Tehran, Iran.

Email:moattar@yahoo.com

Nouri, N., M.Sc. student at the Department of Environmental Engineering, Graduate School of the Environment and Energy, Science and Research Branch, Islamic Azad University, Tehran, Iran.

Email:nahali_2002@yahoo.com

Allahyari, M., M.Sc. student at the Department of Environmental Engineering, Graduate School of the Environment and Energy, Science and Research Branch, Islamic Azad University, Tehran, Iran.

Email:a_maany@hotmail.com

This article should be referenced as follows:

Abbaspour, M.; Jafari, M. J.; Mansouri, N.; Moattar, F.; Nouri, N.; Allahyari, M., (2008). Thermal comfort evaluation in Tehran metro using Relative Warmth Index. Int. J. Environ. Sci. Tech., 5 (3), 297-304. 